\title{
Relation Between Subclinical Endometritis and Reproductive Efficiency in Dairy Cows in Argentina
}

\section{A Rinaudo*, SF Bernardi and PR Marini}

Centro Latinoamericano de Estudios de Problemáticas Lecheras (CLEPL), Faculty of Veterinary Science, National University of Rosario, National Route 33 and Ovidio Lagos (2170) Casilda, Argentina

"Corresponding author: A Rinaudo, Centro Latinoamericano de Estudios de Problemáticas Lecheras (CLEPL), Faculty of Veterinary Science, National University of Rosario, National Route 33 and Ovidio Lagos (2170) Casilda, Argentina, Tel: +543464423377; Fax: +543464422050; E-mail: agustinrinaudo@hotmail.com

Rec date: November 08, 2017; Acc date: November 28, 2017; Pub date: November 29, 2017

Copyright: (C) 2017 Rinaudo A, et al. This is an open-access article distributed under the terms of the Creative Commons Attribution License, which permits unrestricted use, distribution, and reproduction in any medium, provided the original author and source are credited.

\begin{abstract}
The aim of the present study was to analyse the effect of the subclinical endometritis on the postpartum period and its effects on the reproductive efficiency of cows in Argentina. Two hundred and seventy four cows from four dairy farms were used in this study. Cows were kept/maintained on fed grazing with supplementation diet. The diagnosis of subclinical endometritis was carried out by endometrial cytology with $\geq 5 \%$ of polymorphonuclears neutrophils. Positive cows to subclinical endometritis had lower reproductive performance than negative cows. They presented lower pregnancy rates in the first breeding, higher artificial inseminations per pregnancy, and longer calving-pregnancy periods in comparison with healthy cows. Subclinical endometritis has a negative effect on the reproductive performance of the dairy cows and consequently in the dairy farms finances in the animal population studied.
\end{abstract}

Keywords: Dairy cows; Subclinical endometritis; Grazing

\begin{abstract}
Abbreviations
AI: Artificial insemination; AIP: AI per pregnancy; C- $1^{\text {st }}$ SI: Calving- ${ }^{\text {st }}$. service interval; CCI: Calving to conception interval; DIM: Days in milk; PFI: Pregnancy to first insemination; PMN N: Polymorphonuclears neutrophils; SE: Subclinical endometritis.

\section{Introduction}

Dairy milking systems have as one of their main objectives, to maintain milk production of the herds and of the individual cows. It is highly important to make the cows calve at constant intervals between calving [1], being 365 days the optimum interval to achieve one partum per year. Any reproductive problem which will interfere with that objective is of utmost importance. Therefore, specifically the problems within the uterus are one of the reasons of a lower reproductive performance in dairy cows.
\end{abstract}

In recent years, subclinical endometritis (SE) has become more important in the research area of interest of the northern countries, where the dairy systems are characterized by being intensive and in shed systems. Despite the fact that that in Argentina the system is grazing with supplementation, it has also suffered an intensification of the system and that is the reason why SE has become a problem too. The result of the prevalence of SE is variable between different countries. These results show percentages up to 53\% after 40-60 days in milk (DIM) in dairy farms of New York USA area [2] or ranges between 16 to $90 \%$ in Germany [3]. Percentages of 35\% at 20-33 DIM and $34 \%$ at $34-47$ DIM were reported by Kasimanickam et al. [4] in Canadian farms. Surveys carried out in Buenos Aires province (Argentina) show $38 \%$ of SE found at 18-38 DIM and only $19 \%$ from 32-52 days after calving [5].
One of the most remarkable characteristics of the SE is the absence of clinical symptoms. That is why this disease is diagnosed by complementary methods like the endometrial cytology [6]. These samples are obtained by cytobrush of the uterus mucosa. The main aim of this study was to evaluate the effect of the SE in the reproductive efficiency of the postpartum dairy cows.

\section{Materials and Methods}

A total of 274 Holando - Argentino cows from four farms located in the south of Santa Fe province (Argentina) were included in the study. The systems of the farms included in this study reflect the main characteristics of the farms in this area. The cows were fed with alfalfa (Medicago sativa L.), winter crops (Rye Grass), representing these species $50 \%$ of the total feed. Supplementation was based on cracked maize, hay and maize silage, sorgum, commercial feed and oil industry sub-products depending on the farm. The cows were milked twice daily. Cows involved in the study accomplished the following requirements: all of them had between 21-56 DIM, no abnormal partum in this lactation, and without metritis, pyometra, hormonal therapy or antibiotic treatment.

Endometrial cytology samples were taken with cytobrush technique. The cows were diagnosed as ES positive when the cytology resulted in polymorphonuclears neutrophils $(\mathrm{PMN} \mathrm{N}) \geq 5$ [2]. The cows were divided in two subgroups: Healthy and SE cows.

The following reproductive variables were analysed.

Calving- $1^{\text {st }}$. Service Interval $\left(C-1^{\text {st }}\right.$ SI): Days from calving to first artificial insemination (AI).

Pregnancy to First Insemination (PFI): Number of cows pregnant after the first AI over the total number of inseminated cows.

AI per Pregnancy (AIP): Number of artificial insemination (AI) attempts that were necessary to impregnate the cow. 
Page 2 of 4

Calving to Conception Interval (CCI): Days between calving and the conception day.

JMP version 5.0 for Windows (JMP ^, SAS Institute, 2003) was used for the statistical analysis. For the variables Calving-first service interval, AI per pregnancy median and interquartile range and level of significance was estimated by Mann Withney test. Calving to conception interval was used Kaplan-Meier survival analysis. Chi square $\left(\chi^{2}\right)$ was the test chosen to estimate the significance levels between healthy and SE cows in the AI per pregnancy variable. Confidence level for all the analysis was $95 \%$ and standard error of $\alpha<0.05$.

\section{Results}

Prevalence of SE was of $19 \%$ with an individual prevalence of $12.5 \%$, $18 \%, 23 \%$ and $25.8 \%$. There were no significant differences $(p=0.516)$ between them.

Cows were distributed in two groups based on the results of the cytobrush test (healthy and SE cows). Median and interquartile range of the reproductive variables Calving- ${ }^{\text {st }}$ service interval (C- $1^{\text {st }}$ SI) were estimated (Table 1), AI per pregnancy (AIP) (Table 2) and Calving to Conception Interval (CCI) (Table 3).

\begin{tabular}{|l|l|l|}
\hline & Healthy cows & $\begin{array}{l}\text { Subclinical endometritis } \\
\text { cows }\end{array}$ \\
\hline Number of cows & 222 & 52 \\
\hline Median & $85(x)$ & $93(x)$ \\
\hline Interquartile range & 45.5 & 45.8 \\
\hline In the row, different letters mean significant differences, $p<0.05(p=0.532)$ \\
\hline
\end{tabular}

Table 1: Median and interquartile range of $\mathrm{C}-1^{\text {st }} \mathrm{SI}$ expressed in days, per group categorised from the uterine mucosa state.

\begin{tabular}{|l|l|l|}
\hline & Healthy cows & $\begin{array}{l}\text { Subclinical endometritis } \\
\text { Cows }\end{array}$ \\
\hline Number of cows & 222 & 52 \\
\hline Median & $2(x)$ & $4(z)$ \\
\hline Interquartile range & 3 & 5 \\
\hline In the row, different letters mean significant differences, $p<0.001$ \\
\hline
\end{tabular}

Table 2: Median and interquartile range of the AIP per category according to the health of the uterine mucosa.

\begin{tabular}{|l|l|l|}
\hline & Healthy cows & Subclinical endometritis cows \\
\hline & 222 & 52 \\
\hline Number of cows & $113(\mathrm{x})$ & $166(\mathrm{z})$ \\
\hline Median & 94.3 & 145.3 \\
\hline \multicolumn{2}{|l}{ In the row, different letters mean significant differences, $p<0.05$} \\
\hline
\end{tabular}

Table 3: Median and interquartile range of the CCI in days per category according to the health of the uterine mucosa.
Results in Table 1 show that the cows with SE and the healthy cows did not show significant differences $(\mathrm{p}=0.532)$ in the $\mathrm{C}-1$ stSI ( 93 days vs. 85 days).

The hazard of pregnancy at first insemination was also evaluated and the results are expressed in Figure 1.

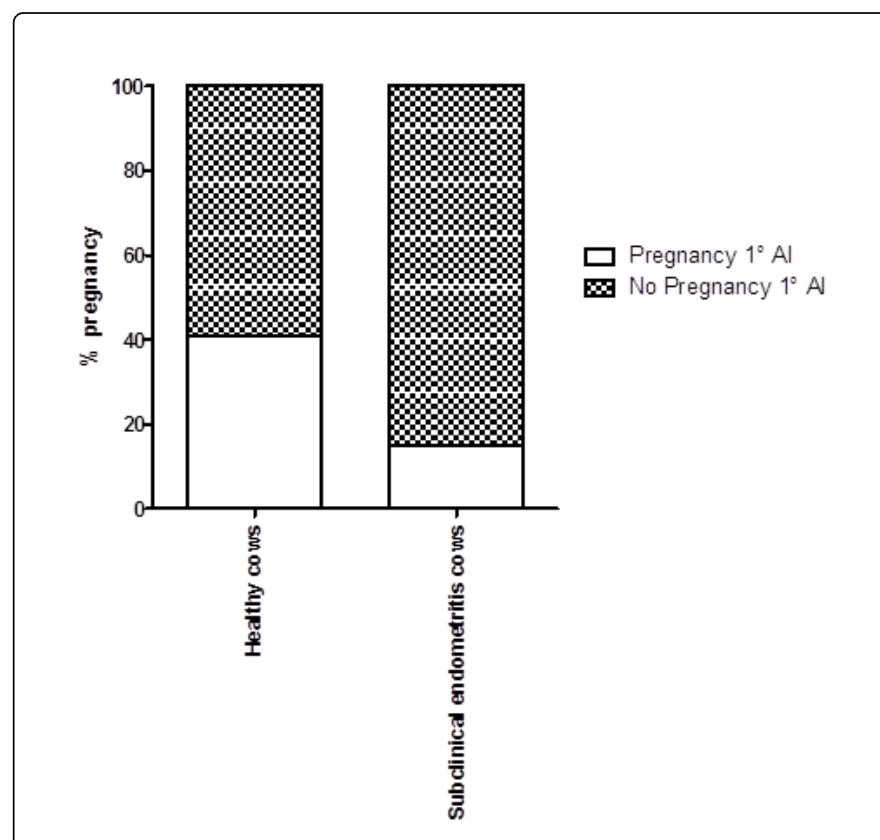

Figure 1: Hazard of PFI for each of the categories according to the health of the uterine mucosa.

Figure 1 shows the distribution of the percentage of pregnant and non pregnant cows at first insemination, where healthy cows achieved higher pregnancy rate $(40.5 \%)$ compared to cows with SE (15.4\%) with statistically significant differences $(\mathrm{p}<0.001)$.

Table 2 shows that the 52 cows with SE required four (4) services to get pregnant, whereas healthy cows required only two (2) services required for that purpose, and this difference was statistically significant $(\mathrm{p}<0.001)$.

Similarly Figure 2 shows the results of the requirements of distributed services in two or less (-) and three or more (+) for both groups of animals (healthy cows and cows with SE), and clearly proves that a higher percentage of cows with SE (59.6\%) require three or more services in relation to only a $39.2 \%$ of healthy cows that needed fewer number of services to achieve pregnancy. This difference is statistically significant $(\mathrm{p}=0.003)$.

Table 3 shows statistically significant difference $(\mathrm{p}<0.001)$ in the CCI between groups of healthy cows and cows with SE. The healthy cows required 113 days to get pregnant and cows with SE needed 166. This difference of 53 days represents over two oestrous cycles more to pregnancy. 
Page 3 of 4

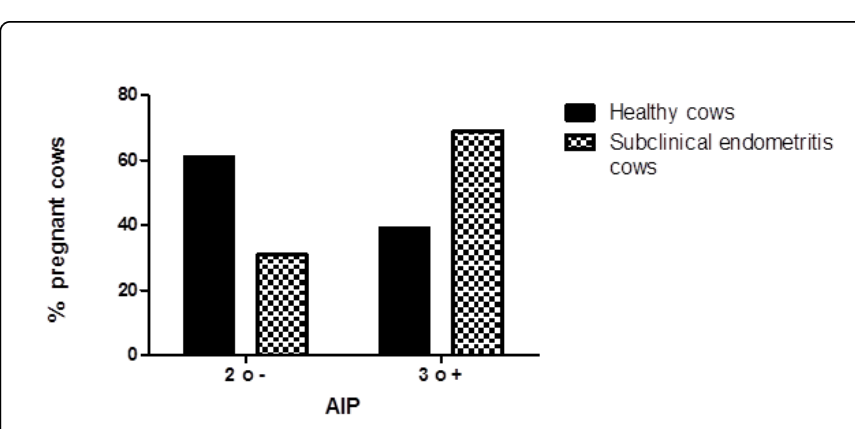

Figure 2: Percentage of pregnant cows by number of services for each of the categories according to the health of the uterine mucosa.

Figure 3 shows the number of cows pregnant and the pregnancy rate for each subgroup and their distribution for each of the ranges of DIM. It distinguishes healthy cows that fail to $30.6 \%$ of pregnancy at $82 \mathrm{DIM}$ while cows with SE only to $11.5 \%$. It also highlights that $91.5 \%$ of healthy cows are not pregnant before the 210 DIM whereas cows with SE and the same amount of DIM could get pregnant only in the $65.4 \%$ of cases (Figure 3). These differences are statistically significant $(\mathrm{p}<0.001)$.

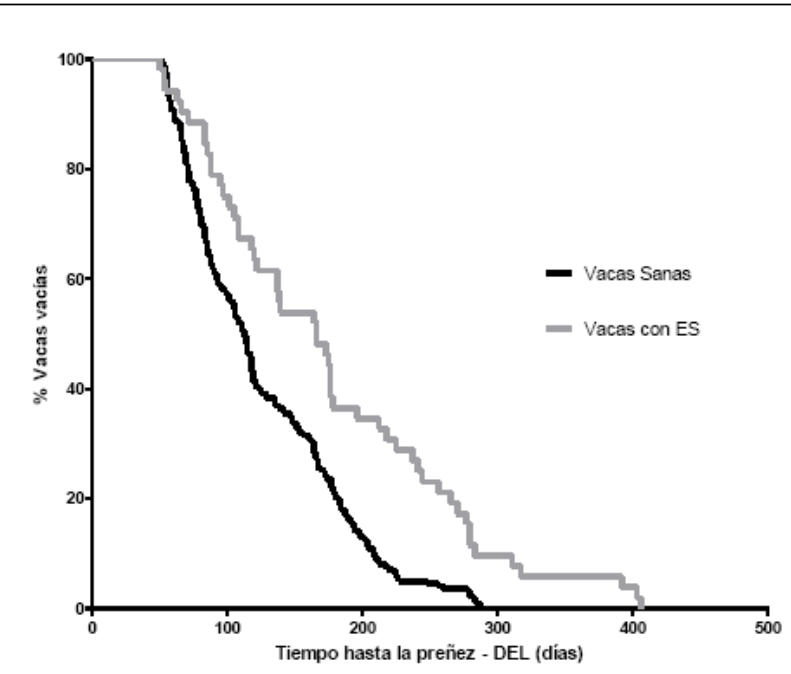

Figure 3: Kaplan-Meier survival graph for time (in days) required each cow from calving to achieve pregnancy by the health of the uterine mucosa.

\section{Discussion}

It was observed that while the cows were inseminated with SE at 93 DIM, and healthy cows at 85 DIM. This difference in the number of days between calving and first service is not statistically significant. This coincides with data reported by Plöntzke et al. [5]. The absence of significant differences is because SE is an entity that has no obvious clinical signs; therefore, cows with SE (situation ignored by the inseminator) will be inseminated together with the healthy cow. The pregnancy rate during the first artificial insemination (\% PFI): $40.5 \%$ of healthy cows became pregnant during the first service, and only $23.1 \%$ of cows with SE achieved pregnancy in the service, and this difference was statistically significant contrary to the findings of Plöntzke et al. who observed no differences between these percentages (28.8\% and $28.6 \%$ healthy cows with SE) [5]. For this reason the services needed to achieve pregnancy in cows with SE increased as compared to healthy cows (3 AIP for cows with SE, and 2 AIP for healthy cows) delaying pregnancy for at least one estrous cycle, thus increasing the open days, adversely affecting the dairy farms' economy. This increase in the AIP is also reflected in the higher percentage of cows with ES (59.6\%) which required 3 or more services in relation to healthy cows (39.2\%) which needed the AIP. The increase in the AIP was also reflected in the calving to conception interval; on average cows with SE delayed conception in approximately 53 days (166 days for cows with SE, and 113 days for healthy cows). This is in line with the results obtained by Madoz et al. [7], who described an increase in days open, although such work is the CCI increased by 52 days, but not consistent with reports on the affection of reproductive performance of $\mathrm{SE}$ cows grazing systems in Argentina [5]. There is a negative reproductive response of cows with SE condition in relation to the cows that do not have this disease entity. For these reasons, the cows with SE increased days open, which impacts negatively on their individual production and the dairy farms' economy in general. Reproductive variables (\% PFI, AIP and CCI) were increased, negatively, in those animals with SE, showing that in cows enrolled for this study, the SE has an impact on reproduction, delaying the next pregnancy and increasing open days. This last statement can be supported with different percentages of pregnancy during postpartum period analyzed. Thus, before the 82 DIM (time limit for the cow to give birth each year) $30.6 \%$ of healthy cows were pregnant whereas only $11.5 \%$ of cows with SE achieved pregnancy. When DIM increase, different percentages appear: each group achieving pregnancy at 210 , $90.5 \%$ of healthy cows and only $69.2 \%$ of cows with SE got pregnant. Thus only $9.5 \%$ of healthy cows were empty at 210 DIM, however $30.8 \%$ of cows with SE left empty after the same period of time. Based on the results we can conclude that SE has a negative effect on reproductive performance of dairy cows and consequently on the economy of the dairy farms in the region studied. For this reason, we consider of great interest the diagnosis of SE through an effective complementary diagnostic method such as the cytobrush, and we encourage further research on this disease entity as one of the causes of poor reproductive performance of dairy cattle.

\section{References}

1. Dijkhuizen AA, Stelwagen J, Renkema JA (1985) Economic aspects of reproductive failure in dairy cattle. I. Financial loss at farm level. Prev Vet Med 3: 251-263.

2. Gilbert RO, Shin ST, Guard CL, Erb HN, Frajblat M (2005) Prevalence of endometritis and its effects on reproductive performance of dairy cows. Theriogenology 64: 1879-1888.

3. Lincke A, Drillich M, Heuwieser W (2007) Subclinical endometritis in dairy cattle and its effect on fertility--a review of recent publications. Berl Munch Tierarztl Wochenschr 120: 245-250.

4. Kasimanickam R, Duffield TF, Foster RA, Gartley CJ, Leslie KE, et al. (2004) Endometrial cytology and ultrasonography for the detection of subclinical endometritis in postpartum dairy cows. Theriogenology 62: 9-23.

5. Plöntzke J, Madoz LV, de la Sota RL, Drillich M, Heuwieser W (2010) Subclinical endometritis and its impact on reproductive performance in grazing dairy cattle in Argentina. Anim Reprod Sci 122: 52-57.

6. Kasimanickam R, Duffield TF, Foster RA, Gartley CJ, Leslie KE, et al. (2005) A comparison of the cytobrush and uterine lavage techniques to 
Citation: Rinaudo A, Bernardi SF, Marini PR (2017) Relation Between Subclinical Endometritis and Reproductive Efficiency in Dairy Cows in Argentina. J Vet Sci Technol 8: 494. doi:10.4172/2157-7579.1000494

Page 4 of 4

evaluate endometrial cytology in clinically normal postpartum dairy cows. Can Vet J 46: 255-259.

7. Madoz LV, Plöntzke J, Albarracin D, Mejia M, Drillich M, et al. (2008)

Prevalence of clinical and subclinical endometritis in dairy cows and the impact on reproductive performance. 16th International Congress on Animal Reproduction, Budapest, Hungary, p: 51. 